\title{
Removal of hexavalent chromium from aqueous solution by crosslinked mangosteen peel biosorbent
}

\author{
K. Huang $\cdot$ Y. Xiu $\cdot$ H. Zhu
}

Received: 28 October 2013/Revised: 3 June 2014 / Accepted: 9 July 2014/ Published online: 25 July 2014

(C) Islamic Azad University (IAU) 2014

\begin{abstract}
In present study the potential of a new biosorbent obtained from mangosteen peel was investigated for the removal of hexavalent chromium and trivalent chromium from the aqueous solutions. The biosorbent was modified by using concentrated sulphuric acid as the crosslinking reagent. Various batch experiments were carried out testing different values of several parameters such as $\mathrm{pH}$, contact time, adsorbent dosages, and metal ion concentration to identify the optimum conditions. The effect of these parameters on the adsorption capacity and selectivity was studied. Results showed that optimum $\mathrm{pH}$ for hexavalent chromium adsorption was 3.0 and adsorption equilibrium was attained in $120 \mathrm{~min}$. The adsorption data were found to fit Langmuir model and pseudo-secondorder equation. The adsorption mechanism for hexavalent chromium was found to be a complex process involving esterification, reduction and ion exchange, while cation exchange is the main route for trivalent chromium adsorption. From the above results, the crosslinked mangosteen peel gel appears to be a potential low-cost and effective adsorbent for hexavalent chromium and trivalent chromium removal from the waste water.
\end{abstract}

Keywords Biosorption - Chromium - Mangosteen peel · Concentrated sulphuric acid

K. Huang $(\bowtie) \cdot$ Y. Xiu $\cdot$ H. Zhu

School of Metallurgical and Ecological Engineering, and State Key Laboratory of Advanced Metallurgy, University of Science and Technology Beijing, Xueyuan Rd. 30, Haidian District, Beijing 100083, China

e-mail: khuang@metall.ustb.edu.cn

\section{Introduction}

Chromium, along with lead, cadmium, arsenic and mercury, is usually ranked as the first-category poisonous chemicals that should be strictly controlled during their usage and discharging (Levankumar et al. 2009; Kratochvil and Volesky 1998; Memon et al. 2009). Chromium usually exists in aqueous medium in $+\mathrm{III}$ and $+\mathrm{VI}$ oxidation states; as to $\mathrm{Cr}(\mathrm{VI})$, it is much more toxic than the trivalent chromium species, and may cause serious damage to kidney, liver and stomach (Inoue et al. 2010; Sarin and Pant 2006). More serious is that $\mathrm{Cr}(\mathrm{VI})$ has been proved to be associated with lung cancer (Mohan et al. 2005). The main source of chromium in the environment is largely from the uncontrolled release of chromium-related industries, such as leather tanning, electroplating, chromium smelting and so on (Gupta et al. 2010). So it is very important to regulate and restrict the whole process of production, usage, and discharging of chromium. The maximum permitted concentration of hexavalent chromium in drinking water suggested by United States Environmental Protection Agency (US EPA) and World Health Organization (WHO) is less than $0.05 \mathrm{mg} \mathrm{L}^{-1}$ (USEPA 2011; WHO 2004).

The most common $\mathrm{Cr}(\mathrm{VI})$ removal technology applied in waste water is reduction by $\mathrm{FeSO}_{4}$ coupled with coagulation. This method has prominent disadvantages such as production of toxic sludge requiring tedious treatment, excessive amounts of $\mathrm{FeSO}_{4}$ and alkaline reagents left in the treated water (Gupta et al. 2010; Jain et al. 2010; Memon et al. 2009; Chand et al. 2009a, b). The other techniques such as reverse osmosis and electrolysis as well as ultrafiltration (Volesky 2007; Demirbas 2008), ion exchange (Gupta et al. 2010; Memon et al. 2009) and adsorption on activated carbon (Chand et al. 2009b; Mohan et al. 2005), may have the problems in high operation and 
maintenance cost, or poor removal efficiency. So it is necessary to develop more cost-effective techniques to remove $\mathrm{Cr}(\mathrm{VI})$ from the waste water.

In recent years, biosorption has attracted many people's interest in water treatment (Ali and Gupta 2006; Ali 2010, 2012; Dhakal et al. 2005; Ghimire et al. 2008a, b; Inoue et al. 2010; Parajuli et al. 2009; Volesky 2007); biosorbents are the key material determining the purification efficiency, operation cost and practical feasibility. In the early periods, fungi and algae were the most common raw materials considered for biosorption, and adsorption mechanisms of various elements were demonstrated in these early studies (Pavasant et al. 2006; Volesky 2007). However, more abundant and easier available sources of biomass for biosorbents preparation, in many countries, are the biowastes from the agro-industry. Huge amounts of agro-wastes provide sufficient raw materials available as much cheaper and more efficient biosorbents. Many kinds of biowastes, as long as the people can think of it, such as orange juice residue (Dhakal et al. 2005), apple juicing residue (Ghimire et al. 2008a), persimmon peel (Inoue et al. 2010), have been tested for their possibility to be used as the biosorbents for removing toxic elements from drinking water, exhibiting exciting prospective for application as biosorbents. For $\mathrm{Cr}(\mathrm{VI})$ removal from drinking water, many biosorbents have been evaluated about their adsorption behavior, and most of them were found to give rise to adsorption coupled with the reduction mechanism, or direct adsorption by esterification process (Chand et al. 2009a, b; Jain et al. 2010; Levankumar et al. 2009; Mohan et al. 2005). Those biomasses containing polyphenols typically demonstrated above-mentioned adsorption behavior (Chand et al. 2009a, b; Inoue et al. 2010), so this gave us an idea to search for the abundant biomaterials to prepare the sorbent, which will have excellent adsorption affinity specially to $\mathrm{Cr}$ (VI). Based on the above idea, in an earlier study we have prepared a kind of sorbent by using mangosteen peel as the raw material (Huang et al. 2013), which is rich of polyphenolic compounds such as anthocyanin, resveratrol etc. (Naczk et al. 2011; Tao et al. 2009; Wang et al. 2012; Zadernowski et al. 2009; Zein et al. 2010), through modification by alkaline soaking, i.e., saponification process. The obtained saponified mangosteen peel gel showed quite excellent adsorption properties for $\mathrm{Cr}(\mathrm{VI})$ removal with high selectivity and large adsorption capacity. The detailed description has been published (Huang et al. 2013), and in present work, we wanted to try another new modification method different from the previous one, which may help to remove low-molecular-weight and water-soluble components in the mangosteen peel more effectively by dehydration with concentrated sulfuric acid, and provide another modification method to make good use of mangosteen peel waste as biosorbent for water treatment.
This study was conducted from September 2011 to July 2013 in the State Key Laboratory of Advanced Metallurgy and school of metallurgical and ecological engineering, University of Science and Technology Beijing, Beijing, China.

\section{Materials and methods}

Preparation of the adsorbent

The mangosteen fruit used in this work was purchased in the local market of Jianxiangqiao fair of Beijing city; it was imported from Thailand, and the peel used for study was obtained after its edible part was consumed. Typical preparation procedure of the adsorption gel was as follows. Fifty grams of wet mangosteen peel were crushed and the obtained purple pulp was dried in an oven at $60{ }^{\circ} \mathrm{C}$ for $12 \mathrm{~h}$. Then the dried powder was mixed homogeneously with $50 \mathrm{~cm}^{3}$ concentrated sulphuric acid (96\%) and kept it in the atmosphere for $24 \mathrm{~h}$ in a glass beaker to allow condensation crosslinking reaction between the various polyphenol and polysaccharide hydroxyl groups in the mangosteen peel. The obtained black residual solid was neutralized by sodium hydroxide solution and then filtered and reconditioned with $1 \mathrm{~mol} \mathrm{~L}^{-1} \mathrm{H}_{2} \mathrm{SO}_{4}$ solution. After stirring for $30 \mathrm{~min}$, the suspension was filtered and washed by hot distilled water several times until the $\mathrm{pH}$ of the filtered liquor approached 7.0. The wet filtered cake was dried in an air convection oven at $60{ }^{\circ} \mathrm{C}$ for $12 \mathrm{~h}$, and the particle size was sieved to $100-200 \mu \mathrm{m}$. The final product of crosslinked mangosteen peel, designated as CMP, is used for the following adsorption tests.

Analysis of $\mathrm{Cr}(\mathrm{VI})$ and total chromium in the test solutions

For the determination of $\mathrm{Cr}(\mathrm{VI})$ concentration in the aqueous solution, the standard diphenylcarbazide method is used (Zhang and Chen 2012). The concentration of Cr(VI) before and after adsorption were analyzed with a ultraviolet-visible spectrophotometer (UNICO-2100, USA) at $540 \mathrm{~nm}$ wavelength by using the pink complex with diphenylcarbazide in acidic solution. The total chromium concentration in the filtrated liquor was measured by a Shimadzu model AAS-6800 atomic absorption spectrophotometer. So based on the above two analysis methods, $\mathrm{Cr}$ (III) concentration can be obtained easily from the difference between the total chromium and the $\mathrm{Cr}(\mathrm{VI})$ concentrations. 
Batch wise adsorption tests

In batch wise adsorption tests, $25 \mathrm{mg}$ of CMP dry gel and $15 \mathrm{~cm}^{3}$ of the individual metal solution at $1.0 \mathrm{mmol} \mathrm{dm}{ }^{-3}$, were mixed and shaken at $293 \mathrm{~K}$ for around $24 \mathrm{~h}$ to attain equilibrium in a thermostatic air bath incubator reciprocating at $140 \mathrm{rpm}$. The initial $\mathrm{pH}$ values of the metal ion solutions were adjusted with $0.1 \mathrm{~mol} \mathrm{dm}^{-3} \mathrm{HCl}$ and $0.1 \mathrm{~mol} \mathrm{dm}^{-3} \mathrm{NaOH}$ solutions, and the $\mathrm{pH}$ values during the adsorption process were kept almost constant by using $0.1 \mathrm{~mol} \mathrm{dm}^{-3}$ HEPES (2-[4-(2-hydroxylethyl)-1-piperazinyl] ethanesulfonic acid) as the buffer solution for each test sample. After adsorption, the metal ion solution samples were filtered and the metal concentration in the filtrated liquor was measured for evaluate the adsorption efficiency. The amount of adsorption for metal ions was calculated according to the following equations.

$A=\left(C_{i}-C_{e}\right) / C_{i} \times 100$

$Q=\left(C_{i}-C_{e}\right) \times V / W$

where $A$ is the adsorption percentage of metal ions on the gel (\%), $Q$ denotes the amount of metal ion adsorbed per unit mass of the adsorbent ( $\mathrm{mol} \mathrm{kg}{ }^{-1}$ or mol kg${ }^{-1}$ ), $V$ is the solution volume $\left(\mathrm{dm}^{3}\right), W$ is the dry mass of the adsorbent (kg or $\mathrm{g}$ ), $C_{i}$ and $C_{e}$ represent the metal ion concentrations in the solution before and after adsorption $\left(\mathrm{mol} \mathrm{dm}{ }^{-3}\right.$ or $\mathrm{mg} \mathrm{dm}^{-3}$ ), respectively.

Reusability test of the eluted adsorbents

To check the reusability of the adsorbent, CMP adsorbent was subjected to repeated adsorption and elution experiments as follows. Twenty five milligrams CMP gel were shaken with $15 \mathrm{~cm}^{-3} 1 \mathrm{mmol} \mathrm{dm}^{-3} \mathrm{CrO}_{4}{ }^{2-}$ solution at $\mathrm{pH}$ 1 for $24 \mathrm{~h}$, then the mixture was filtrated and the residue gel was washed by double-distilled water three times to remove the physically adsorbed ions. The metal ion-loaded gel was then shaken with $25 \mathrm{~cm}^{-3} 0.5 \mathrm{~mol} \mathrm{dm}{ }^{-3}$ hydrochloric acid in a conical flask at $293 \mathrm{~K}$ for $2 \mathrm{~h}$. Above adsorption and elution experiments were repeated, and the metal ion concentration before and after adsorption was measured each time to evaluate the adsorption efficiency.

\section{Results and discussion}

\section{Characterization of the adsorbent}

Figure 1 shows the SEM photo of the surface of crosslinked mangosteen peel gel. It is clear that the surface morphology of the gel is rough which is favorable for metal ions to be trapped and adsorbed on the gel. It also looks not

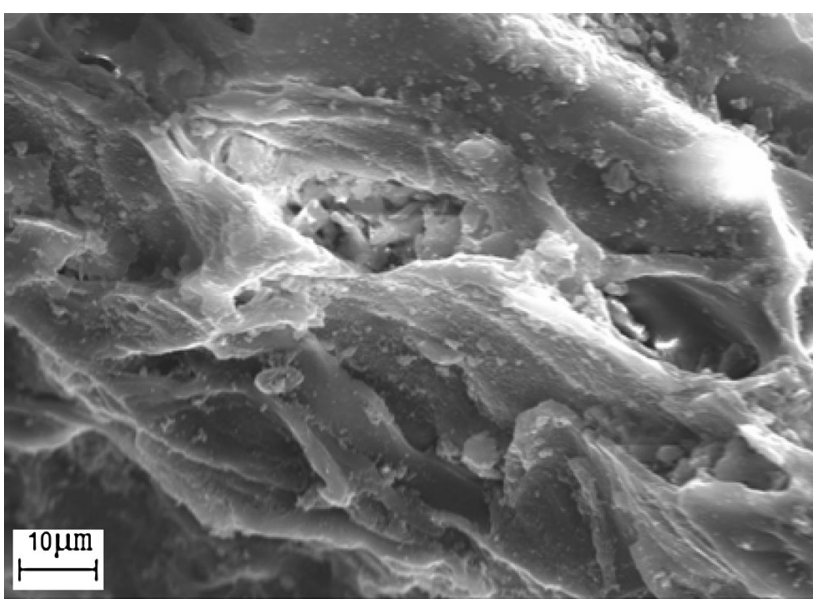

Fig. 1 Scanning electron micrograph of the surface of CMP gel

so compact, which will be helpful for metal ions to diffuse or penetrate into the inner parts of the adsorbent particles and good for the fast adsorption.

Figure 2 shows the FTIR spectra of CMP gel before and after adsorption of $\mathrm{Cr}(\mathrm{VI})$ at $\mathrm{pH}$ 3.0. The broad absorption peak at $3,345 \mathrm{~cm}^{-1}$ can be attributed to the $\mathrm{O}-\mathrm{H}$ stretching vibration due to inter and intra-molecular hydrogen bonding of alcohols, phenols and carboxylic acids, and the absorption peaks at 2,970 and $2,932 \mathrm{~cm}^{-1}$ can be assigned to the $\mathrm{C}-\mathrm{H}$ stretching of non ionic carboxylic groups, while peaks at $1,700 \mathrm{~cm}^{-1}$ corresponds to the asymmetric and symmetric stretching vibration of $\mathrm{C}=\mathrm{O}$ bond in ionic carboxylic groups of - $\mathrm{COO}-$, respectively. The peaks at $1,450 \mathrm{~cm}^{-1}$ ( $\mathrm{C}=\mathrm{C}$ bond $), 1,286 \mathrm{~cm}^{-1}(\mathrm{O}-\mathrm{H}$ bond $)$ and 883 and $619 \mathrm{~cm}^{-1}(\mathrm{C}-\mathrm{H}$ bond $)$ can be assigned to the phenolic group (Inoue et al. 2010), and they are found to become weaker or even disappear after adsorption of $\mathrm{Cr}(\mathrm{VI})$, indicating the effective adsorption of chromium ions on the CMP gel.

\section{Effect of $\mathrm{pH}$}

The adsorption behavior of the saponified mangosteen peel gel for hexavalent and trivalent chromium at different equilibrium $\mathrm{pH}$ values is shown in Fig. 3. It can be found that two species of chromium demonstrate quite different adsorption patterns. It is clear that the CMP gel exhibits high selectivity for $\mathrm{Cr}(\mathrm{VI})$ over $\mathrm{Cr}$ (III) at $\mathrm{pH}<4$, while at $\mathrm{pH}>4$, the high selectivity was conversely changed for $\mathrm{Cr}(\mathrm{III})$ over $\mathrm{Cr}(\mathrm{VI})$. Obviously, the solution $\mathrm{pH}$ plays a very key role in this adsorption process. Quite similar adsorption behavior has also been reported for the polyphenol-containing biosorbents such as persimmon peel gel, grape peel gel and saponified mangosteen peel gel (Inoue et al. 2010; Chand et al. 2009a; Huang et al. 2013). The contrasting adsorption behavior for $\mathrm{Cr}(\mathrm{VI})$ and $\mathrm{Cr}(\mathrm{III})$ can 
Fig. 2 Fourier transform infrared (FTIR) spectra of crosslined mangosteen peel (CMP) gel before and after adsorption of chromium ions at $\mathrm{pH} 3.0$

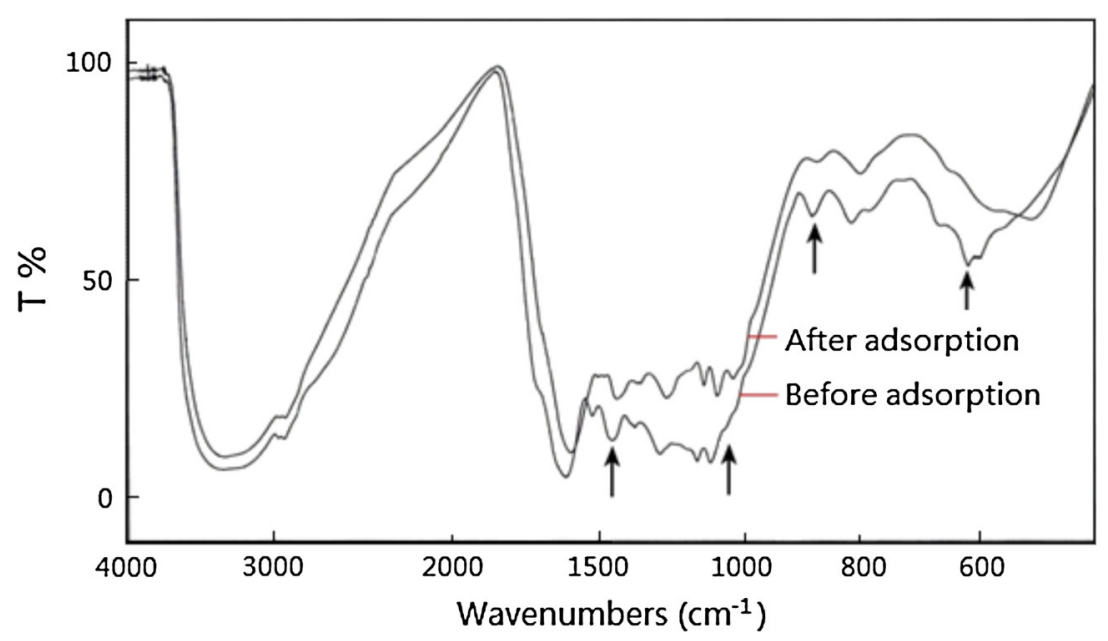

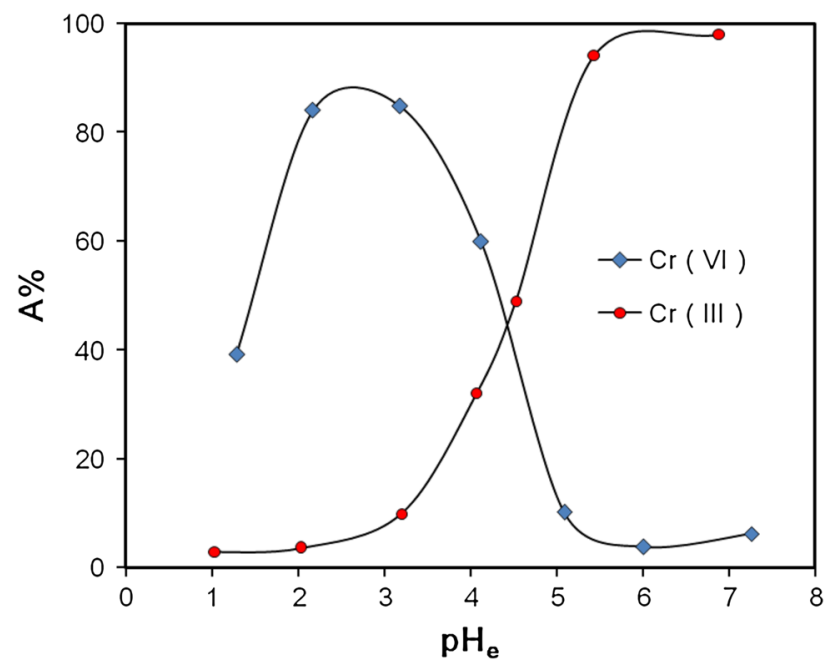

Fig. 3 Effect of equilibrium $\mathrm{pH}$ on the percentage adsorption of $\mathrm{Cr}(\mathrm{VI})$ and $\mathrm{Cr}(\mathrm{III})$ ions on CMP gel. (Dry weight of the gel $=25 \mathrm{mg}$, volume of solution $=15 \mathrm{~cm}^{3}$, initial concentration of metal ions $=1 \mathrm{mmol} \mathrm{dm}^{-3}$, contact time $=4 \mathrm{~h}$, temp. $=293 \mathrm{~K}$ )

be ascribed to the different uptake mechanisms during their adsorption process. Usually, according to the related research work (Inoue et al. 2010; Chand et al. 2009a), it can be proposed that adsorption of $\mathrm{Cr}(\mathrm{VI})$ may occur through a direct esterification reaction between the $\mathrm{HCrO}_{4}{ }^{-}$and the phenol groups on the gel, and then the captured $\mathrm{Cr}(\mathrm{VI})$ might be reduced to $\mathrm{Cr}(\mathrm{III})$ by the electron rich polyphenolic ring in the gel and the produced $\mathrm{Cr}^{3+}$ would be adsorbed onto the CMP gel at high $\mathrm{pH}$ and desorbed at low pH (Inoue et al. 2010; Chand et al. 2009a; Huang et al. 2013), as shown in Fig. 3. So we can see that adsorption of $\mathrm{Cr}(\mathrm{VI})$ may include the following three steps, i.e., esterification, reduction, and uptake of produced $\mathrm{Cr}^{3+}$. As described in many studies (Inoue et al. 2010; Chand et al. 2009a, b; Huang et al. 2013), $\mathrm{H}^{+}$is favorable for the esterification and reduction steps while impedes the uptake of $\mathrm{Cr}^{3+}$ for it is believed to proceed according to a cation exchange mechanism. At low $\mathrm{pH}$ less than 3 , as seen in Fig. $3, \mathrm{Cr}^{3+}$ is hardly adsorbed by the CMP gel, so it can be concluded that the contribution to the removal of $\mathrm{Cr}(\mathrm{VI})$ in this $\mathrm{pH}$ range is mainly from the esterification process. And at lower $\mathrm{pH}$, more $\mathrm{H}^{+}$will promote more $\mathrm{Cr}(\mathrm{VI})$ to be transformed into $\mathrm{Cr}(\mathrm{III})$, so the $\mathrm{A} \%$ (percent adsorption) will decrease in this acidic solution, and at $\mathrm{pH}$ higher than 3 , the esterification process will be inhibited due to the high concentration of $\mathrm{OH}^{-}$, leading to the rapid decrease of $\mathrm{A} \%$ at $\mathrm{pH}$ higher than 3.0 as shown in Fig. 3. So actually there is a competitive interaction between the esterification and reduction, and $\mathrm{H}^{+}$plays a key role in the adsorption process of $\mathrm{Cr}(\mathrm{VI})$.

In order to elucidate the reduction mechanism of $\mathrm{Cr}(\mathrm{VI})$ during the adsorption onto the CMP gel, both $\mathrm{Cr}(\mathrm{VI})$ and $\mathrm{Cr}$ (III) concentrations in solution were measured as shown in Fig. 4. In this experiment, an initial solution containing only $\mathrm{Cr}(\mathrm{VI})$ was used to contact with CMP gel, and sampled for measurement after a certain time interval. The total chromium concentration in solution was measured by an atomic absorption spectrophotometer, and the $\mathrm{Cr}(\mathrm{VI})$ concentration was measured by the diphenylcarbazide method. The difference of total chromium and $\mathrm{Cr}(\mathrm{VI})$ was the $\mathrm{Cr}(\mathrm{III})$ concentration. Figure 4 shows that $\mathrm{Cr}(\mathrm{VI})$ concentration will decrease rapidly when adsorption occurs, while the concentration of $\mathrm{Cr}(\mathrm{III})$ will increase quickly from zero to a constant. In this experiment, there's no trivalent chromium in the initial solution, but it appears in the adsorption process, which proves the occurrence of reduction. This figure also shows that the final chromium concentration was actually the concentration of $\mathrm{Cr}$ (III) which has negligible adsorption onto the CMP gel at $\mathrm{pH}$ 3.0. Based on above analysis, it can be seen that the adsorption mechanism of $\mathrm{Cr}(\mathrm{VI})$ onto $\mathrm{CMP}$ gel is quite complex and different from that of the $\mathrm{Cr}$ (III) adsorption process. 


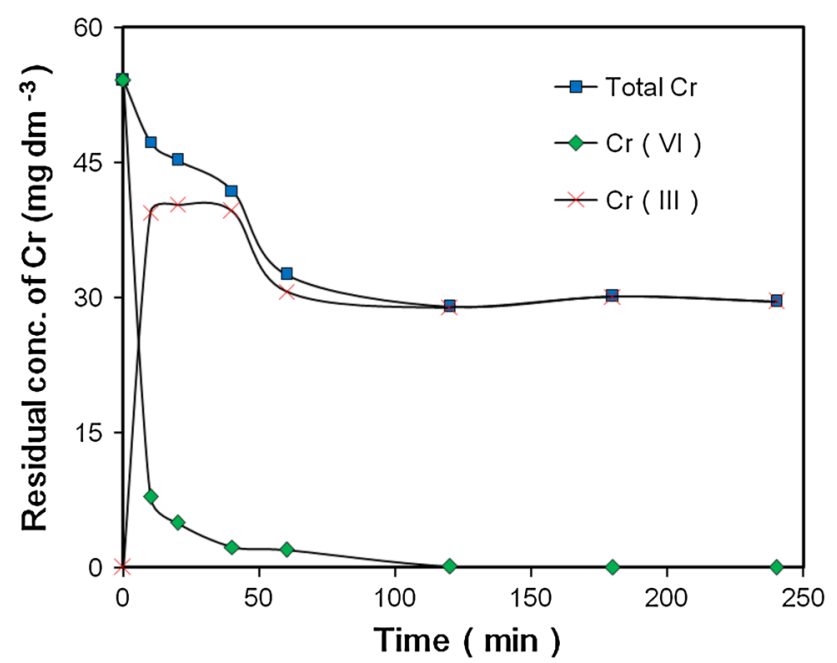

Fig. 4 Time variation of the concentrations of $\mathrm{Cr}(\mathrm{VI})$ and $\mathrm{Cr}(\mathrm{III})$ as well as total chromium during adsorption. (Dry weight of the gel $=25 \mathrm{mg}$, volume of solution $=15 \mathrm{~cm}^{3}$, initial concentration of metal ions $=1 \mathrm{mmol} \mathrm{dm}^{-3}, \mathrm{pH}=3.0$, temp. $=293 \mathrm{~K}$ )

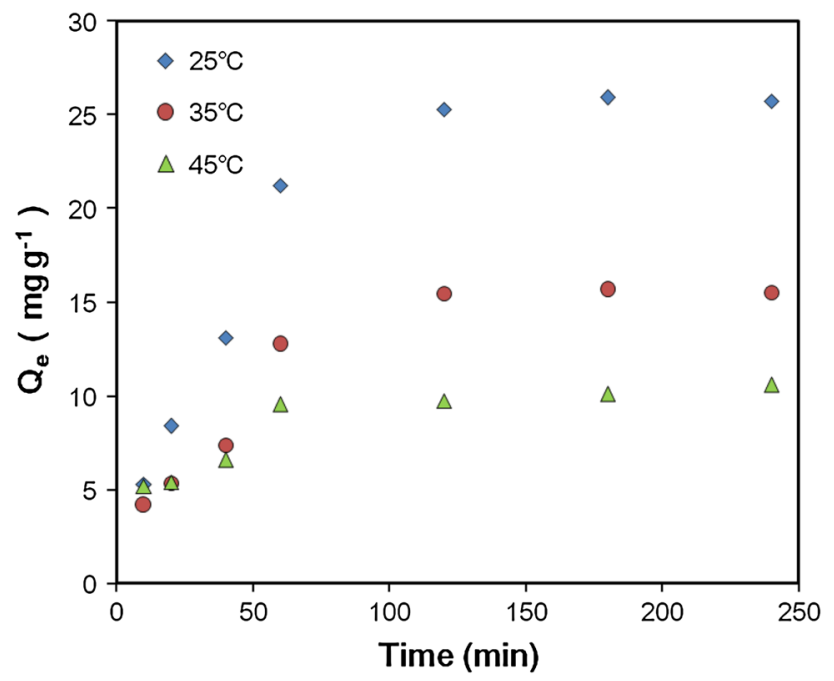

Fig. 5 Effect of temperature on the percentage adsorption of $\mathrm{Cr}(\mathrm{VI})$ on CMP gel. (Dry weight of the gel $=25 \mathrm{mg}$, volume of solution $=15 \mathrm{~cm}^{3}$, initial concentration of metal ions $=1 \mathrm{mmol} \mathrm{dm}^{-3}$, $\mathrm{pH}=3.0$, temp. $=293 \mathrm{~K})$

\section{Effect of temperature}

Figure 5 shows the effect of temperature on the \% adsorption of $\mathrm{Cr}(\mathrm{VI})$ onto CMP gel at $\mathrm{pH} 3$. It can be found that the adsorption capacity will decrease when temperature increases, which suggests that the adsorption of $\mathrm{Cr}(\mathrm{VI})$ is an exothermic process. It was further found that above adsorption data can be described by pseudo-second-order kinetics equation, as shown in Fig. 6. Based on the results, an Arrhenius formula was used to evaluate the apparent activation energy to be $46.93 \mathrm{~kJ} \mathrm{~mol}^{-1}$ by plotting

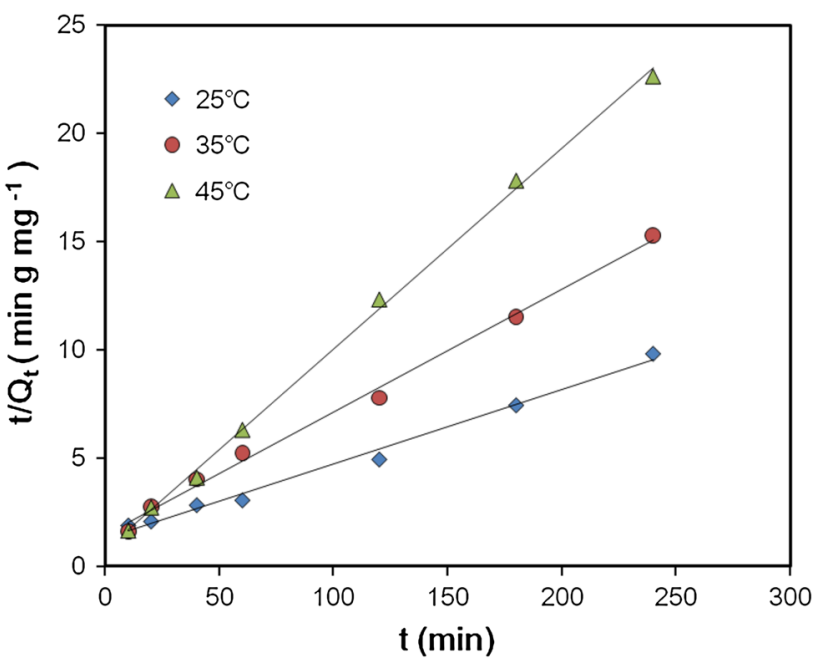

Fig. 6 Pseudo-second-order kinetics plots at different temperatures for $\mathrm{Cr}(\mathrm{VI})$ adsorption on CMP gel (conditions as Fig. 5)

$\ln K$ versus $1 / T$, as indicated in Table 1 ; this suggests that the key step to limit the whole adsorption process is a chemical reaction, probably esterification and reduction steps. In fact the scale value of activation energy gives an indication on the mechanism of the adsorption process: values higher than $12 \mathrm{~kJ} \mathrm{~mol}^{-1}$ indicate that chemical reaction is the controlling step, whereas values lower than $12 \mathrm{~kJ} \mathrm{~mol}^{-1}$ suggest that diffusion is the controlling step (Li 1992). The adsorption activation energy value is quite close to that of the saponified mangosteen peel gel with $42.73 \mathrm{~kJ} \mathrm{~mol}^{-1}$ (Huang et al. 2013). Then $\ln K_{c}$ was plotted versus $1 / T$ (Table 1), and from the fitting line the enthalpy of the adsorption process was evaluated to be $-86.95 \mathrm{~kJ} \mathrm{~mol}^{-1}$, indicating that the adsorption of $\mathrm{Cr}(\mathrm{VI})$ onto CMP gel is an exothermic process.

\section{Effect of gel dosage}

Figure 7 shows the effect of CMP gel dosage on the \% adsorption of $\mathrm{Cr}(\mathrm{VI})$. It can be seen that only $1 \mathrm{~g} \mathrm{dm}^{-3}$ can make the \% adsorption to reach a constant. Though the initial concentration of $\mathrm{Cr}(\mathrm{VI})$ is only $2.7 \mathrm{mg} \mathrm{dm}^{-3}$, the residual chromium concentration is still kept at $0.5 \mathrm{mg} \mathrm{dm}^{-3}$ even adding more gel in the solution. It is clear that at $\mathrm{pH}$ near 3.0, most of the $\mathrm{Cr}(\mathrm{VI})$ will be uptaken by the esterification process, while a part of $\mathrm{Cr}(\mathrm{VI})$ will also be reduced to $\mathrm{Cr}$ (III) which is hardly adsorbed by CMP gel in this case and is left in the residual solution as trivalent chromium. The reduced amount of $\mathrm{Cr}(\mathrm{VI})$ into $\mathrm{Cr}(\mathrm{III})$ is mainly determined by solution $\mathrm{pH}$ when the CMP gel is sufficient, so the residual chromium concentration had the same values whatever the gel dosage. 
Table 1 Calculation values of apparent activation energy and enthalpy of the adsorption process

\begin{tabular}{lllll}
\hline $\begin{array}{l}\text { Equation } \\
\text { models }\end{array}$ & $\begin{array}{l}\text { Fitting model of the } \\
\text { data }\end{array}$ & $\begin{array}{l}\text { Calculation energy values, } \\
\mathrm{kJ} \mathrm{mol}^{-1}\end{array}$ & $\begin{array}{l}\text { Correlation coefficient, } \\
R^{2}\end{array}$ & Remarks \\
\hline $\ln K$ vs $1 / T$ & $y=-5,645 x+12.11$ & 46.93 & 0.909 & $\begin{array}{l}\text { Apparent activation energy for } \\
\text { adsorption } \\
\text { Enthalpy value of adsorption }\end{array}$ \\
\hline $\ln K_{c}$ vs $1 / T$ & $y=10,458 x-34.29$ & -86.95 & 0.939 & Ealp \\
\hline
\end{tabular}

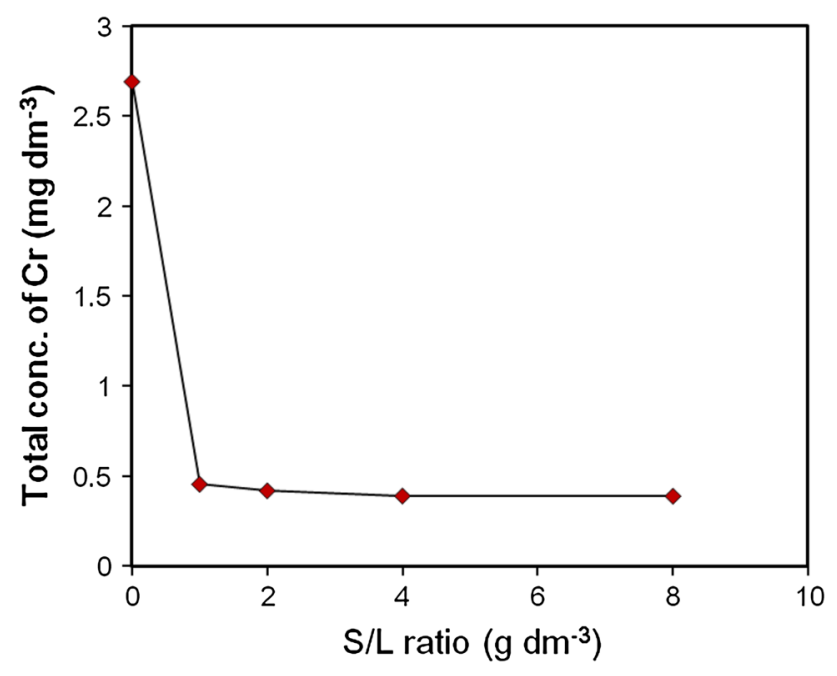

Fig. 7 Effect of dosage on the percentage adsorption of $\mathrm{Cr}(\mathrm{VI})$ on CMP gel. (Dry weight of the gel $=25 \mathrm{mg}$, volume of solution $=15 \mathrm{~cm}^{3}$, initial concentration of metal ions $=2.7 \mathrm{mg} \mathrm{dm}^{-3}$, $\mathrm{pH}=3.0$, temp. $=293 \mathrm{~K}$, contact time $=4 \mathrm{~h}$ )

\section{Adsorption isotherms for $\mathrm{Cr}(\mathrm{VI})$}

The isotherm test was made to evaluate the adsorption capacity of the CMP gel to uptake $\mathrm{Cr}(\mathrm{VI})$ from aqueous solution. Isotherm tests were carried out batch wisely using various concentrations of $\mathrm{Cr}(\mathrm{VI})$ ranging from 0.1 to $10 \mathrm{mmol} / \mathrm{L}$ at solution $\mathrm{pH} 3$. The adsorption isotherms on the saponified mangosteen peel gel are shown in Fig. 8a, from which the adsorption of $\mathrm{Cr}(\mathrm{VI})$ seems to occur according to a Langmuir-type adsorption, i.e., the adsorbed amount increases with increasing concentration of metal ion at low metal ion concentration while it tends to reach a constant value at high metal ion concentration.

So the adsorption isotherms were evaluated using Langmuir model (Inoue et al. 2010) represented as Eq. (3), as depicted in Fig. 8b.

$C_{e} / Q_{e}=1 /\left(b Q_{m}\right)+C_{e} / Q_{m}$

where $Q_{e}\left(\mathrm{~mol} \mathrm{~kg}^{-1}\right.$ or $\left.\mathrm{g} \mathrm{kg}^{-1}\right)$ is the mass of adsorbed metal ions per gram of adsorbent, $C_{e}\left(\mathrm{~mol} \mathrm{~L}^{-1}\right.$, or denoting as $\mathrm{M}$ ) is the concentration of metal ion in aqueous solution at equilibrium, $Q_{m}\left(\mathrm{~mol} \mathrm{~kg}^{-1}\right)$ is the maximum capacity of adsorbent, and $b\left(\mathrm{~L} \mathrm{~kg}^{-1}\right)$ is the binding constant.
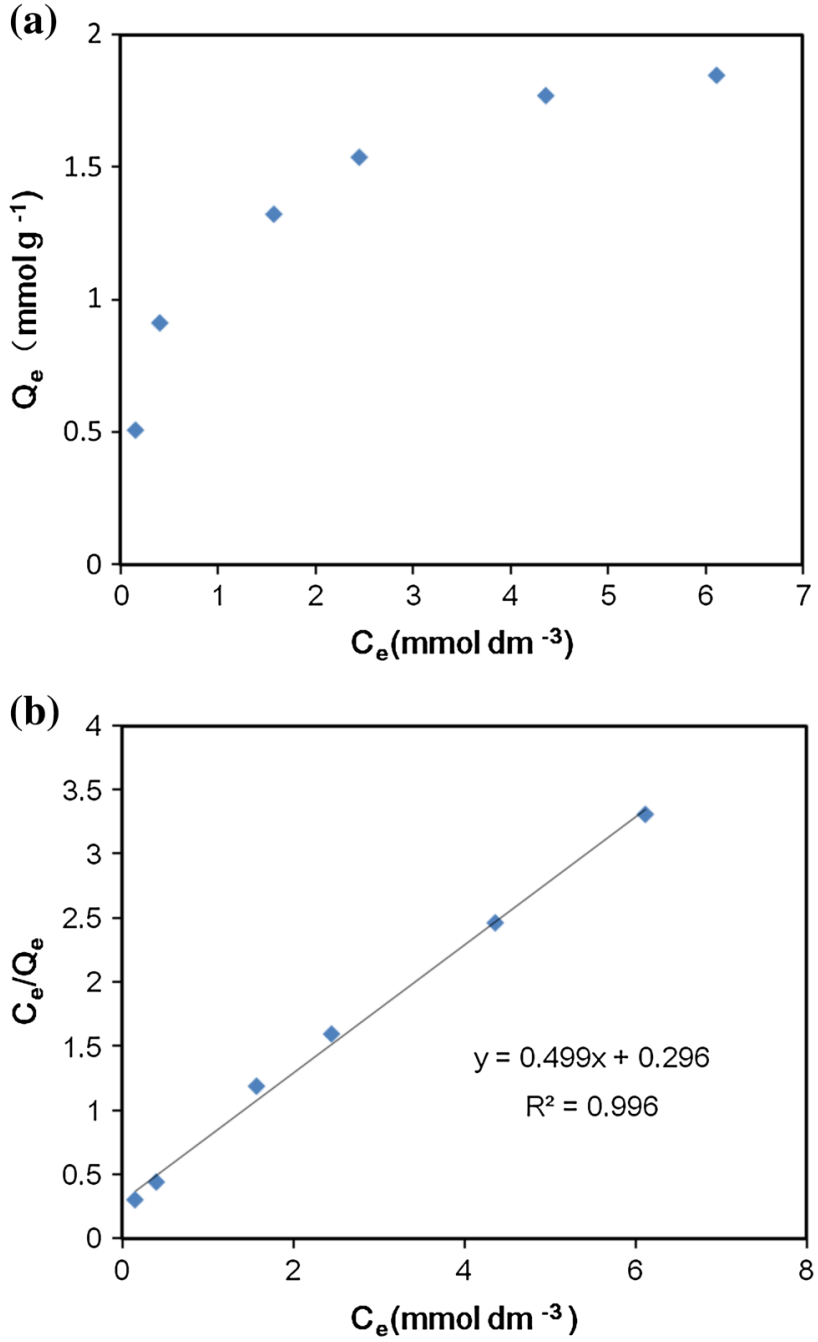

Fig. 8 Adsorption isotherms of $\mathrm{Cr}(\mathrm{VI})$ on CMP gel. a Isotherm curve and $\mathbf{b}$ Langmuir plot. (Dry weight of the gel $=25 \mathrm{mg}$, volume of solution $=15 \mathrm{~cm}^{3}, \mathrm{pH}=3.0$, temp. $=293 \mathrm{~K}$, contact time $=4 \mathrm{~h}$ )

It can be seen that the experimental data are well fitted by the Langmuir Eq. (3) as shown in Fig. 8b, where linear relationship is observed with high correlation coefficients $\left(R^{2}=0.996\right)$. The value of $Q_{e}$ was evaluated to be $2.0 \mathrm{~mol} \mathrm{~kg}^{-1}$.

Comparison of the CMP gel with other biosorbents

Table 2 lists the maximum adsorption capacities of the various adsorbents including CMP gel. This table shows that the 
Table 2 Comparison of the maximum adsorption capacity for $\mathrm{Cr}(\mathrm{VI})$ on different adsorbents

\begin{tabular}{|c|c|c|c|c|}
\hline Adsorbents & $\mathrm{pH}$ & $\begin{array}{l}\text { Temp. } \\
\left({ }^{\circ} \mathrm{C}\right)\end{array}$ & $\begin{array}{l}\text { Adsorption } \\
\text { capacity } \\
\left(\mathrm{mol} \mathrm{kg}^{-1}\right)\end{array}$ & References \\
\hline Persimmon tannin & 2.0 & 30 & 5.27 & $\begin{array}{r}\text { Nakajima and } \\
\text { Baba (2004) }\end{array}$ \\
\hline $\begin{array}{l}\text { Ocimum } \\
\text { americanum L. } \\
\text { seed pods }\end{array}$ & 1.5 & 27 & 1.60 & $\begin{array}{l}\text { Levankumar } \\
\text { et al. (2009) }\end{array}$ \\
\hline $\begin{array}{l}\text { Crosslinked } \\
\text { persimmon gel }\end{array}$ & 1.0 & 30 & 7.18 & $\begin{array}{l}\text { Inoue et al. } \\
(2010)\end{array}$ \\
\hline $\begin{array}{l}\text { Crosslinked grape } \\
\text { gel }\end{array}$ & 4.0 & 30 & 1.91 & $\begin{array}{c}\text { Chand et al. } \\
\text { (2009a) }\end{array}$ \\
\hline Barley straw & 2.0 & 30 & 1.68 & $\begin{array}{l}\text { Chand et al. } \\
\text { (2009b) }\end{array}$ \\
\hline $\begin{array}{l}\text { Saponified } \\
\text { mangosteen } \\
\text { peel }\end{array}$ & 3.0 & 20 & 1.99 & $\begin{array}{l}\text { Huang et al. } \\
\text { (2013) }\end{array}$ \\
\hline $\begin{array}{l}\text { Crosslinked } \\
\text { mangosteen } \\
\text { peel }\end{array}$ & 3.0 & 20 & 2.00 & This study \\
\hline
\end{tabular}

polyphenol-bearing biosorbents have higher adsorption capacities than other biosorbents such as seed pods and barley straw. It is also found that at $\mathrm{pH} 3$, the mangosteen peel saponified with alkaline reagent (Huang et al. 2013), and crosslinked by concentrated sulfuric acid (present study) have quite close adsorption capacity for $\mathrm{Cr}(\mathrm{VI})$, which suggests that these two modification methods both effectively activated the adsorption ligands contained in the mangosteen peel. As compared to other adsorbents, the preparation of CMP gel is quite simple and economic, just using mangosteen peel and a small amount of concentrated sulfuric acid as the crosslinking reagent, which indicates great potential for its application to cost-effective removal of $\mathrm{Cr}(\mathrm{VI})$ from various industrial effluents.

\section{Reusability of the eluted adsorbents}

To check the reusability of the CMP gel, CMP adsorbent was subjected to repeated adsorption and elution experiments. The adsorption capacity of the CMP gel was found to be practically kept more than $90 \%$ after 10 cycles of use, so it can be seen that multiple use of the adsorbent is feasible.

\section{Conclusion}

An excellent adsorbent for $\mathrm{Cr}(\mathrm{VI})$ removal was prepared by using mangosteen peel as the raw material through a crosslinking process with concentrated sulphuric acid as the modifier. The synthesis process is simple, economical and non-poisonous, and the prepared adsorbent shows high affinity, large loading capacity for $\mathrm{Cr}(\mathrm{VI})$, which might be an alternative to the costly resins or activated carbon for the removal of $\mathrm{Cr}(\mathrm{VI})$. The adsorption isotherm indicates that the removal of $\mathrm{Cr}(\mathrm{VI})$ can be described by a Langmuir model, and the maximum adsorption capacity for $\mathrm{Cr}(\mathrm{VI})$ at pH 3.0 was evaluated to be $2.0 \mathrm{~mol} \mathrm{~kg}^{-1}$ for $\mathrm{Cr}(\mathrm{VI})$. The adsorption of $\mathrm{Cr}(\mathrm{VI})$ on CMP gel may take place according to the following two routes, i.e., one is through an esterification reaction, and the other is a reduction of the esterified $\mathrm{Cr}(\mathrm{VI})$ into $\mathrm{Cr}(\mathrm{III})$ by the polyphenol components contained in the mangosteen peel followed by an adsorption of reduced $\mathrm{Cr}$ (III) onto the gel. So an optimal $\mathrm{pH}$ actually depends on competitive result of above two adsorption processes which are both highly $\mathrm{pH}$-dependent. For its low cost and large adsorption capacity for $\mathrm{Cr}(\mathrm{VI})$ under acidic conditions, CMP gel prepared by the proposed process might find good application in the treatment of various $\mathrm{Cr}(\mathrm{VI})$-bearing waste water.

Acknowledgments The present work was financially supported by an initiation grant-in-aid for returned Chinese scholars founded by Education Ministry of China (No. 11140065), and the special fundamental funds by Beijing Education Committee.

\section{References}

Ali I (2010) The quest for active carbon adsorbent substitutes: inexpensive adsorbents for toxic metal ions removal from wastewater. Sep Purif Rev 39(3-4):95-171

Ali I (2012) New generation adsorbents for water treatment. Chem Rev 112(10):5073-5091

Ali I, Gupta VK (2006) Advances in water treatment by adsorption technology. Nat Protoc 1(6):2661-2667

Chand R, Narimura K, Kawakita H, Ohto K, Watari T, Inoue K (2009a) Grape waste as a biosorbent for removing $\mathrm{Cr}(\mathrm{VI})$ from aqueous solution. J Hazard Mater 163(1):245-250

Chand R, Watari T, Inoue K, Torukai T, Yada M (2009b) Evaluation of wheat straw and barley straw carbon for $\mathrm{Cr}(\mathrm{VI})$ adsorption. Sep Purif Technol 65(3):331-336

Demirbas A (2008) Heavy metal adsorption onto agro-based waste materials: a review. J Hazard Mater 157(2-3):220-229

Dhakal RP, Ghimire KN, Inoue K (2005) Adsorptive separation of heavy metals from an aquatic environment using orange waste. Hydrometallurgy 79(3-4):182-190

Ghimire KN, Huang K, Inoue K, Ohto K, Kawakita H, Harada H, Morita M (2008a) Heavy metal removal from contaminated scallop waste for feed and fertilizer application. Bioresour Technol 99(7):2436-2441

Ghimire KN, Inoue K, Ohto K, Hayashida T (2008b) Adsorption study of metal ions onto crosslinked seaweed Laminaria japonica. Bioresour Technol 99(1):32-37

Gupta VK, Rastogi A, Nayak A (2010) Adsorption studies on the removal of hexavalent chromium from aqueous solution using a low cost fertilizer industry waste material. J Colloid Interface Sci 342(1):135-141

Huang K, Xiu Y, Zhu H (2013) Selective removal of Cr(VI) from aqueous solution by adsorption on mangosteen peel. Environ Sci Pollut Res 20(9):5930-5938 
Inoue K, Paudyal H, Nakagawa H, Kawakita H, Ohto K (2010) Selective adsorption of chromium (VI) from zinc (II) and other metal ions using persimmon waste gel. Hydrometallurgy 104(2):123-128

Jain M, Garg VK, Kadirvelu K (2010) Adsorption of hexavalent chromium from aqueous medium onto carbonaceous adsorbents prepared from waste biomass. J Environ Manage 91(4):949-957

Kratochvil D, Volesky B (1998) Advanced in the biosorption of heavy metals. Trends Biotechnol 16(7):291-300

Levankumar L, Muthukumaran V, Gobinath MB (2009) Batch adsorption and kinetics of chromium (VI) removal from aqueous solutions by Ocimum americanum L. seed pods. J Hazard Mater 161(2-3):709-713

Li H (1992) Fundamental principle and practice in the leaching process. Rare Metals Cem Carbides 110(9):28-34

Memon JR, Memon SQ, Bhanger MI, Ei-Turki A, Hallam KR, Allen GC (2009) Banana peel: a green and economical sorbent for the selective removal of $\mathrm{Cr}(\mathrm{VI})$ from industrial wastewater. Colloids Surf B 70(2):232-237

Mohan D, Singh KP, Singh VK (2005) Removal of hexavalent chromium from aqueous solution using low-cost activated carbons derived from agricultural waste materials and activated carbon fabric cloth. Ind Eng Chem Res 44(4):1027-1042

Naczk M, Towsend M, Zadernowski R, Shahidi F (2011) Proteinbinding and antioxidant potential of phenolics of fruit (Garciniamangostana). Food Chem 128(2):292-298

Nakajima A, Baba Y (2004) Mechanism of hexavalent chromium adsorption by persimmon tannin gel. Water Res 38(12):2859-2864

Parajuli D, Khunathai K, Adhikari CR, Inoue K, Ohto K, Kawakita H, Funaoka M, Hirota K (2009) Total recovery of gold, palladium, and platinum using lignophenol derivative. Miner Eng 22(13): 1173-1178

Pavasant P, Apiratikul R, Sungkhum V, Suthiparinyanont P, Wattanachira S, Marhaba TF (2006) Biosorption of $\mathrm{Cu}^{2+}, \mathrm{Cd}^{2+}$, $\mathrm{Pb}^{2+}$, and $\mathrm{Zn}^{2+}$ using dried marine green macroalga Caulerpa lentillifera. Bioresour Technol 97(18):2321-2329

Sarin V, Pant KK (2006) Removal of chromium from industrial waste by using eucalyptus bark. Bioresour Technol 97(1):15-20

Tao Y, Huang L, Wei BY, Teng JW (2009) Study on the compositions and antioxidant activity of plant polyphenol from pericarp of Garcinia mangostana. Food Ind Sci Technol 30(12):126-129

USEPA (2011) Ground Water and Drinking Water, Current Drinking Water Standards, EPA 816-F-02

Volesky B (2007) Biosorption and me. Water Res 41(18):4017-4029

Wang JJ, Shi QH, Zhang W, Sanderson BJS (2012) Anti-skin cancer properties of phenolic-rich extract from the pericarp of (Garcini amangostana Linn.). Food Chem Toxicol 50(9):3004-3013

World Health Organization (WHO) (2004) Guidelines for drinkingwater quality, vol 1, 3rd edn. Recommendations, Geneva, p 334

Zadernowski R, Czaplicki S, Naczk M (2009) Phenolic acid profiles of fruits (Garcinia mangostana). Food Chem 112(3):685-689

Zein R, Suhaili R, Earnestly F, Indrawati, Munaf E (2010) Removal of $\mathrm{Pb}(\mathrm{II}), \mathrm{Cd}(\mathrm{II})$ and $\mathrm{Co}(\mathrm{II})$ from aqueous solution using Garcinia mangostana L fruit shell. J Hazard Mater 181(1-3):52-56

Zhang Y, Chen XY (2012) Research on determination of chromium (VI) in surface water environment. Appl Chem Ind 41(2):349-351 